www.jmscr.igmpublication.org

Impact Factor 3.79

Index Copernicus Value: 5.88

ISSN (e)-2347-176x ISSN (p) 2455-0450

crossref DOI:_http://dx.doi.org/10.18535/jmscr/v4i02.32

\title{
Dexmedetomidine And Fentanyl For Epidural Anesthesia With 0.5\% Levobupivacaine For Lower Limb Orthopedic Surgey - A Comparitive Evaluation
}

\author{
Authors \\ Dr Mahilamani PP ${ }^{1}$, Dr Ranjan John ${ }^{2}$
}

${ }^{1}$ Assisstant Professor, Dept of Anesthesiology \& Critical care Medicine, SMIMS, Kulasekaram, TamilNadu

${ }^{2}$ Senior consultant, Department of Anesthesiology, Cosmopolitan Hospital, Trivandrum, Kerala

\begin{abstract}
Background: Addition of adjuvants to local anesthetic enhance the quality and duration of epidural anesthesia. The present study aimed to compare the hemodynamic, sedative, anesthetic and analgesic potentiating effects of Dexmedetomidine and Fentanylwith 0.5\% Levobupivacaine for lower limb orthopedic surgery. Method: 60 consented patients of both gender aged 25-60, ASA I and II physical status who underwent lower limb orthopedic surgery were randomly divided into two groups. Patients received epidural study solution of $0.5 \%$ Levobupivacaine $14 \mathrm{ml}$ either with $25 \mathrm{mcg}$ DexmedetomidineGroup-D or $50 \mathrm{mcg}$ Fentanyl Group- F. The total volume was kept $15 \mathrm{ml}$.Time of onset, level of sensory and motor blockade and duration of analgesia were assessed. Perioperative sedation score, hemodynamic parameters, respiratory efficiency and side effects were also noted. Data obtained was compiled with SPSS 16.0 with student $t$ - test and Chi-squaretest. Value of $p<0.05$ was considered significant. Result: The demographic profile was comparable between groups. Onset of sensory blockade andtime to achieve complete motor blockade were significantly earlier and duration of motor blockade and analgesia were prolonged significantly in groupD $(P<0.001)$. Sedation scorewas better in Group D and highly significant statistically $(P<0.001)$. Hemodynamic changes were comparable between two groups. Incidence of nausea, vomiting, pruritus, and shivering werehigh in Group F and dry mouth was high in Group D. Conclusion: Dexmedetomidine was better than Fentanyl as an epidural adjuvant for providing early onset of sensory blockade, prolonged motor blockade and post-operative analgesia and better sedation without any major side effects.

Keywords: Epidural anesthesia, Dexmedetomidine, Fentany, Levobupivacaine, Orthopedic Surgery.
\end{abstract}

\section{INTRODUCTION}

Epidural technique is effective for providing anesthesia and post-operative analgesia for prolonged surgeries. It offers superior pain relief, attenuation of surgical stress response ${ }^{[1]}$, faster recovery of gut function [2], reduction in thromboembolic and cardiovascular complications, but it is frequently associated with hemodynamic instability due to use of large volume of local anesthetics ${ }^{[3,4]}$.

Levobupivacaine, a stereo isomer of Bupivacaine, an amide local anaesthetic showed a profile close to bupivacaine in terms of onset, quality, duration of sensory blockade, but with cardiac and neurotoxic adverse effects. The clinical data showed its efficacy and safety for regional 
anaesthetic techniques with minimal hemodynamic changes. Its low lipid solubility leads to greater sensory motor differentiation by blocking sensory nerve fibers than motor fibers, early recovery of motor functions is associated with decreased incidence of venous thromboembolism ${ }^{[5,6]}$.

Various drugs have been used as epidural adjuvants to enhance the quality and duration of surgical anesthesia. Sedation, stable hemodynamics and an ability to provide prolonged post-operative analgesia are the main desirable quality of the epidural adjuvant ${ }^{[7]}$. The additionofopioids provides a dose sparing effect of local anaesthetic and superior analgesia but there is a possibility of an increased incidence of pruritus, urinary retention, vomiting and respiratory depression ${ }^{[8,9]}$. Fentanylacts as $\mu$ receptor agonist to enhance the analgesia. Dexmedetomidine is a highly selective $\alpha 2$ adrenergic receptor agonist with a relatively high $\alpha 2 / \alpha 1$ activity. It acts on pre and post synaptic nerve terminal and central nervous system to decrease the sympathetic outflow and norepinephrine release causing sedation, anxiolysis, analgesia, sympatholytic and hemodynamic effects ${ }^{[10,11,12]}$. Motor blockade tends to be more dense with Dexmedetomidine causes a manageable hypotension and bradycardia, but is devoid of opioid related side effects like respiratory depression, nausea and vomiting ${ }^{[13]}$. The exact dose equivalents of these drugs are yet to be studied.

Keeping the merits of levobupivacaine and the adjuvants in consideration, we planned to evaluate and compare the efficiency of dexmedetomidine and fentanyl as adjuvant to epidural levobupivacaine for lower limb orthopedic surgery.

\section{Aim and Objectives:}

To evaluate and compare the clinical efficacy of dexmedetomidineand fentanyl as adjuvants to epidural levobupivacaine for lower limb orthopedic surgery.

\section{MATERIALS AND METHODS}

\section{Inclusion criteria:}

After obtaining the approval of institutional ethics committee and written informed consent, 60 patients of both gender ASA physical status 1and 2 aged 25-60 years weighing 50-70 kg and height $150-175 \mathrm{cms}$ were enrolled in this study.

\section{Exclusion criteria:}

Patients with diabetes mellitus, hypertension, severe cardiac and respiratory disease, renal and hepatic disease, spinal deformity, neurological disorders, infection at the site of epidural, coagulation or bleeding disorders, allergic to local anesthetics, patients in whom the epidural block failed or when other analgesic or anaesthetic agent have been supplemented and who refused the technique were excluded from the study.

\section{METHOD}

Pre anaesthetic evaluation was done, all patients were reassured and explained in detail about the anaesthetic procedure, method of assessing the sensory and motor blockade and the possible complications. Informed consent was taken, all patients were given tab.ranitidine $150 \mathrm{mg}$ and tab.alprazolam $0.25 \mathrm{mg}$ night before surgery and two hours prior to surgery.

Patients were divided randomly into two groups of 30 each. Group D - patient received epidural study solution, $14 \mathrm{ml} 0.5 \%$ levobupivacaine with $25 \mathrm{mcg}$ dexmedetomidine and group F- received $14 \mathrm{ml} \quad 0.5 \%$ levobupivacaine with $50 \mathrm{mcg}$ Fentanylkeeping a total volume of $15 \mathrm{ml}$ in both the groups. The drug was prepared by ananesthesiologist who was blind to the study protocol.

After the arrival of patients into the operation theatre, a multipara meter monitor was attached and baseline vital parameters like ECG, heart rate, noninvasive blood pressure,spo2, respiratory rate were recorded and monitored throughout the perioperative period. $18 \mathrm{G} \mathrm{IV} \mathrm{cannula} \mathrm{was} \mathrm{secured}$ and infused $10 \mathrm{ml} / \mathrm{kg}$ of Ringer lactate solution 1 hour before starting anesthesia. With all aseptic precautions epidural space identified at L3--4 
orL4--5 space using 18G Touhys needle by loss of resistance to air technique after skin infiltration with $2 \%$ lignocaine in the sitting position. An epidural catheter was introduced $3-4 \mathrm{~cm}$ into the epidural space and secured. Position of the epidural catheter was checked by aspiration for blood and CSF. A test dose of $3 \mathrm{ml} 2 \%$ lignocaine with $5 \mathrm{mcg} / \mathrm{ml}$ epinephrine was administered to detect the intravenous injection and the patients were placed supine. After three minutes the patients received the study solution according to the randomization schedule. The following parameters were observed. Time of onset of sensory blockade at t10, maximum sensory level achieved, time to complete motor blockade, time to 2 segmental dermatomes regression, time to first rescue analgesia, level of sedation, heart rate, NIBP, SPO 2 and respiratory rate.

Sensory blockade was assessed by bilateral pin prick method using a short beveled 26G hypodermic needle. Motor blockade by modified Bromage scale(0-no paralysis, 1- unable to raise extended leg but able to flex the knee, 2- able to flex the knee, 3-unable to flex the ankle- no movement) at 5, 10, 15,20,25,30 minutes after epidural administration of the study solution .

Level of sedation was assessed by Ramsay sedationscore (grade1 awake, conscious, no sedation -slightly restless,grade2- calm and compose, grde3- awake on verbal command, grade-4 awake on gentle tactile stimulation, grade5-awake on vigorous shaking, grade6 unarousable) just before starting the procedure, every 20minutes intra operatively and hourly during the post-operative period .

Hemodynamic parameters, heart rate, ECG, NIBP, $\mathrm{SPO} 2$, respiratory rate were monitored continuously and recordings were made every 5 minutes till the completion of surgery and every 30 minutes post operatively. For the present study hypotension was defined as fall in blood pressure of more than $20 \%$ of baseline value or less than $100 \mathrm{~mm} \mathrm{Hg}$ and was treated with IV fluid and incremental doses of ephedrine 3-6 mg IV. Bradycardia heart rate less than 60/min was treated with $0.6 \mathrm{mg}$ of atropine intravenously. Supplemental oxygen was given to all patients.

Side effects like nausea, vomiting, pruritus, shivering, urinary retention and respiratory depression were carefully observed, recorded and treated accordingly.

\section{STATISTICAL ANALYSIS}

The data obtained was compiled systematically and analyzed using SPSS 16.0. The parametric data were analyzed using student's t-test and nonparametric data using Chi-square test. $\mathrm{P}$ value of $<0.05$ was considered statistically significant. Microsoft word and Excel have been used to generate graphs, tables etc.

\section{RESULT}

Totally 60 patients were enrolled for the study and randomly divided into two groups. The demographic profile was comparable between groups and did not show any statistical difference.

(Table 1)

\section{Table 1}

\begin{tabular}{|l|l|l|}
\hline \multicolumn{2}{|l|}{ Demographic profile of patients } \\
\hline Parameter & Group D & Group F \\
\hline Age in years & $36.62 \pm 9.66$ & $34.26 \pm 6.86$ \\
\hline Weight $(\mathrm{kg})$ & $66.84 \pm 10.2$ & $64.26 \pm 11.52$ \\
\hline Height $(\mathrm{cm})$ & $155.2 \pm 4.29$ & $156.4 \pm 4.68$ \\
\hline ASA (112) & $22 / 8$ & $21 / 9$ \\
\hline Male | Female & $24 / 6$ & $23 / 7$ \\
\hline Duration of procedure (min) & $112.42 \pm 15.31$ & $115 \pm 13.34$ \\
\hline
\end{tabular}

SD-Standard deviation, D-Dexmedetomidine, F-Fentanyl.

ASA-American society of anesthesiologists. 


\section{JMSCR Vol||4||Issue||02||Page 9280-9287||February}

Table 2

\begin{tabular}{|c|c|c|c|}
\hline \multicolumn{4}{|l|}{ Sensory and motor blockade characteristics } \\
\hline Parameters & Group D & Group F & $P$ value \\
\hline Onset time of sensory block at $\mathrm{T} 10(\mathrm{~min})$ & $7.11 \pm 2.12$ & $9.13 \pm 2.69$ & $0.036^{*}$ \\
\hline Maximum sensory level attained & T8-T9 & T8-T9 & \\
\hline $\begin{array}{l}\text { Time to achieve maximum sensory blockade } \\
\text { (min) }\end{array}$ & $12.38 \pm 4.49$ & $15.61 \pm 4.37$ & $0.021 *$ \\
\hline $\begin{array}{l}\text { Time for complete motor blockade (Bromage } \\
\text { 3) }\end{array}$ & $18.16 \pm 4.8$ & $21.67 \pm 5.6$ & $0.038^{*}$ \\
\hline Time to two segmental dermatomes regression & $139.31 \pm 11.21$ & $109.3 \pm 10.48$ & $0.004 * *$ \\
\hline Total duration of motor blockade & $257.3 \pm 21$ & $213.5 \pm 36$ & $0.001 * *$ \\
\hline Time to first rescue analgesia & $332.7 \pm 16.9$ & $291.6 \pm 18.4$ & $0.001 * *$ \\
\hline
\end{tabular}

*Statistically significant $* \mathrm{P}<0.05$ statistically significant $* * \mathrm{P}<0.001 \quad$ statistically highly significant. Data expressed as mean \pm SD. Sensory and motor blockade characteristics are shown in Table2. The mean time of onset of sensory analgesia at T10 dermatome was sooner in group D than Group $\mathrm{F}$ and was statistically significant. Though the total volume injected and the maximum sensory level achieved in both the groups were comparable $\mathrm{T} 8 \mathrm{~T} 9$, time to attain maximum sensory level in Group $D$ was significantly earlier than Group F. The mean time for complete motor blockade was also earlier in Group D and was statistically significant. Time for two segmental dermatomes regression was prolonged in Group D. The total duration of motor blockade and time to first rescue analgesia were also prolonged and were statistically highly significant.

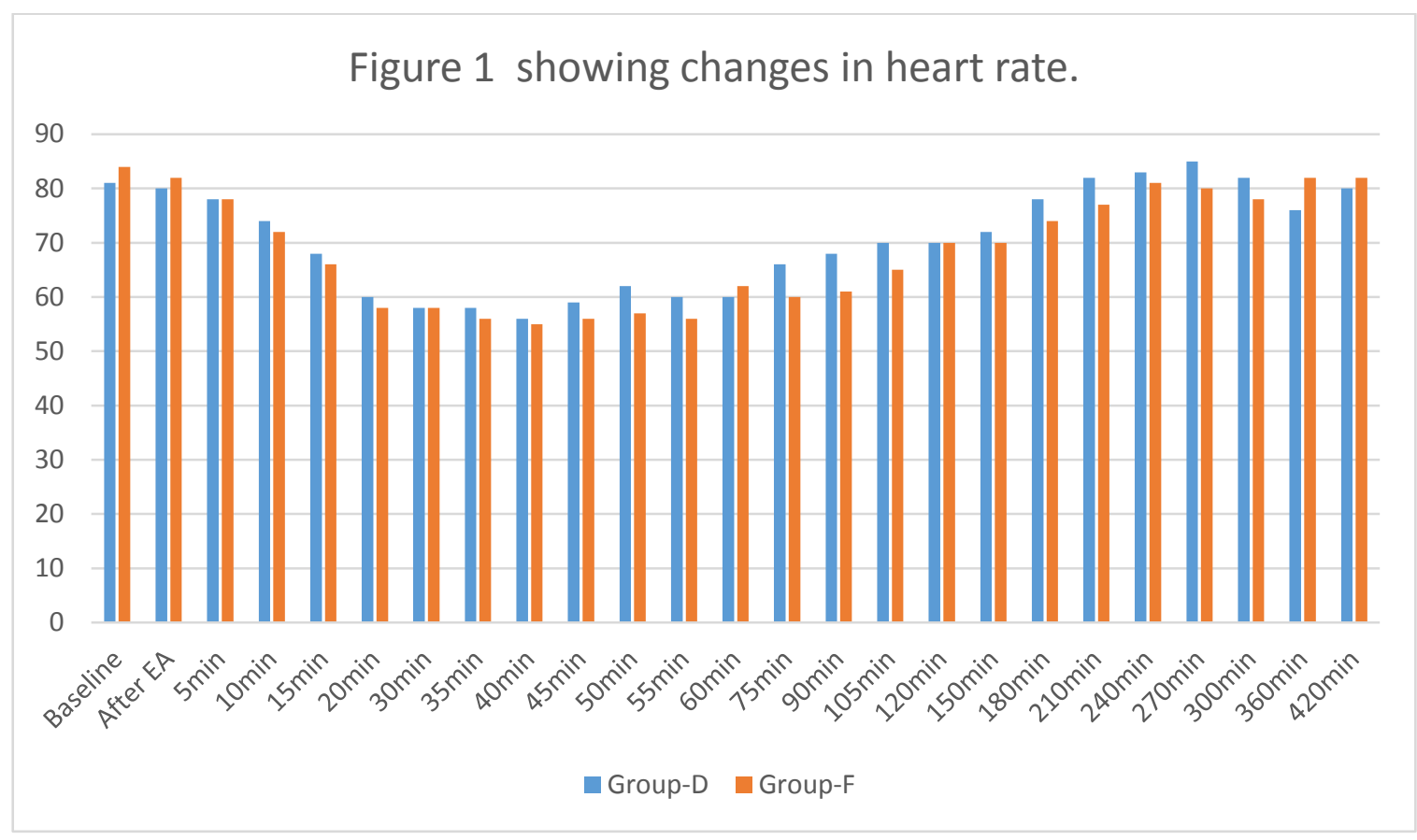


Figure 2 showing changes in mean arterial pressure

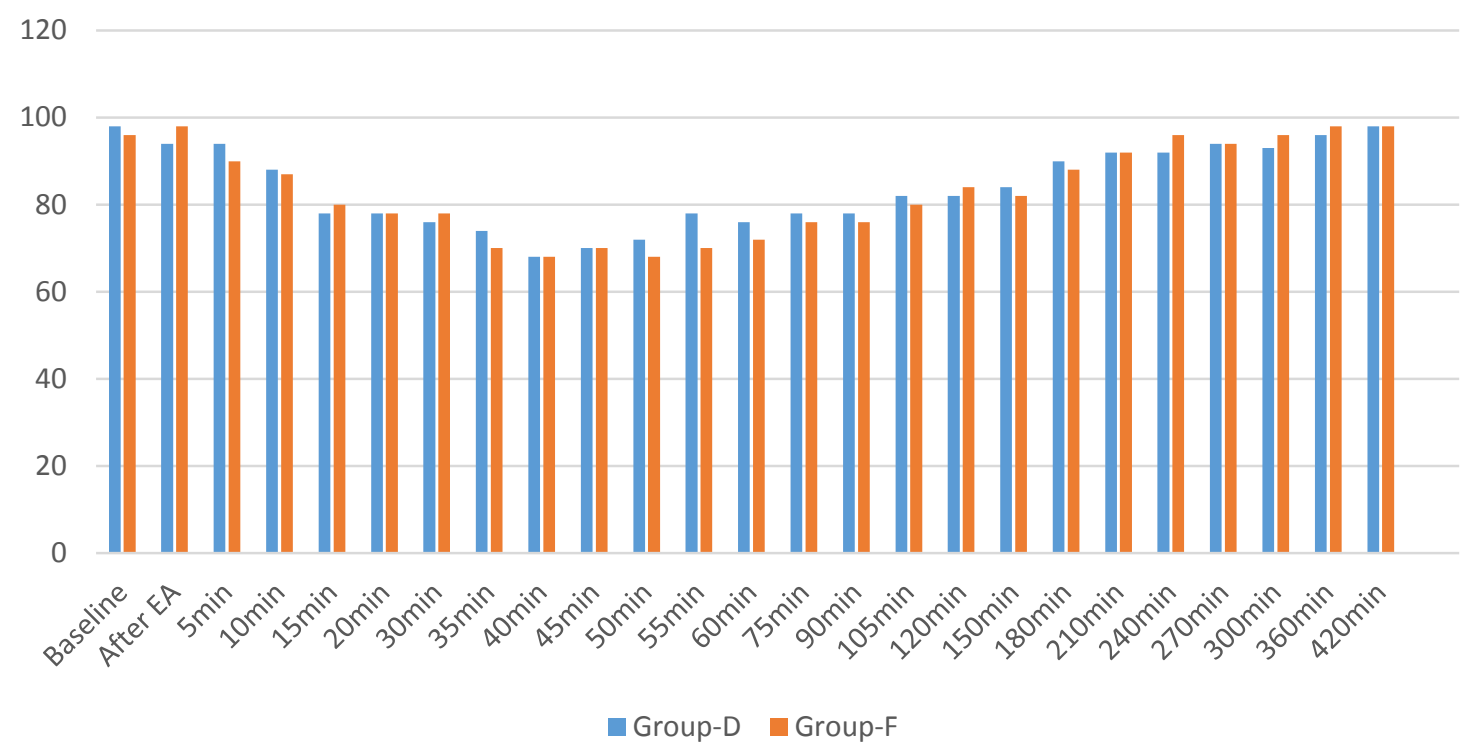

Both the groups were comparable with respect to statistically significant reduction from the baseline heart rate, systolic, diastolic, mean arterial blood values. (Figure 1 and 2) pressure and were stable and did not show

Table 3 Comparison of Intraoperative sedation scores.

\begin{tabular}{|l|cr|rr|c|}
\hline $\begin{array}{l}\text { Sedation } \\
\text { score }\end{array}$ & \multicolumn{2}{|l|}{$\begin{array}{l}\text { Group D } \\
\text { Number of patients }\end{array} \quad \%$} & $\begin{array}{l}\text { Group F } \\
\text { Number of patients }\end{array}$ & P value \\
\hline 1 & 2 & 7 & $21^{* *}$ & 70 & $<0.001$ \\
\hline 2 & $12^{* *}$ & 40 & 6 & 20 & $<0.001$ \\
\hline 3 & $15^{* *}$ & 50 & 3 & 10 & $<0.001$ \\
\hline 4 & 1 & 3 & 0 & & \\
\hline 5 & 0 & & 0 & & \\
\hline
\end{tabular}

$* * \mathrm{P}<0.001$ statistically highly significant.

Ramsay sedation score showed highly significant difference between groups (table-3). In group D $40 \%$ and $50 \%$ of patients exhibited grade 2 and grade 3 sedation whereas in group $\mathrm{F}$ that was $20 \%$ and $10 \%$ only. Only $7 \%$ of the patients in group D had sedation scores of 1 compared to $70 \%$ of patients in group $\mathrm{F}$ which was also statistically highly significant.

Table 4: Side effects

\begin{tabular}{|l|l|l|}
\hline Side effects & Group D & Group F \\
\hline Nausea & 2 & 3 \\
\hline Vomiting & 1 & 2 \\
\hline Shivering & 1 & 2 \\
\hline Pruritus & 0 & 2 \\
\hline Dry mouth & 3 & 0 \\
\hline Respiratory depression & 0 & 0 \\
\hline Urinary retention & 3 & 3 \\
\hline
\end{tabular}

The side effects like nausea, vomiting, shivering and urinary retention noted in patients of both groups and the incidence were comparable (table4). Two patients in group $\mathrm{F}$ developed pruritus during the post-operative period and 3 patients in group D had dryness of mouth. No episodes of hypotension, bradycardia and respiratory depression was noted in any of the patients. Respiratory rate and oxygen saturation was also comparable in both the groups.

\section{DISCUSSION}

Addition of adjuvant to local anaesthetic for epidural anesthesia enhances the onset of sensory and motor blockade and reduce the effective dose of local anesthetics. Early mobilization and rehabilitation with minimum pain and discomfort 
is the most desirable feature in modern orthopedic surgery.

We selected epidural anesthesia during this study deliberately to avoid the sudden hemodynamic changes induced by spinal anesthesia and to provide the post-operative analgesia.

The newer amide local anaesthetic levobupivacaine, like bupivacaine provide similar onset of sensory blockade and duration of analgesia, but the onset of motor blockade is delayed and less dense. The onset of sensory blockade begins at 10-25 minutes after epidural administration with 2-4 hours duration ${ }^{[5]}$. The cardiovascular and central nervous system toxicity are also less.

Local anesthetics acts by blocking sodium channel. Fentanyl acts as agonist of $\mu$ opioid receptors to enhance the analgesia. The dorsal nerve roots contain opioid binding sites. Fentanyl, either acts directly in the spinal nerve or by penetrating the duramater to act at the spinal roots $[14,15]$

Dexmedetomidine acts on both pre and post synaptic sympathetic nerve endings and control nervous system by decreasing the sympathetic outflow, norepinephrine release to cause sedation, analgesia, and hemodynamic effects. It acts peripherally by blocking conduction through $\mathrm{A} \delta$ and $\mathrm{C}$ fibers to enhance the effects of local anaesthetic without increasing the incidence of side effects. Synergism between epidural local anesthetics and opioids is well established but evidence regarding combination of dexmedetomidine with local anaesthetic is scarce in literature.

In the present study the demographic profile in both the groups were comparable.

We observed early onset of sensory and motor blockade, early attainment of maximum sensory level in dexmedetomidine group compared to fentanyl group. So the onset of blockade was hastened by dexmedetomidine. Sukhminder Bajwa et al ${ }^{[16]}$ also found the early onset of analgesia and motor blockade in epidural dexmedetomidine when used with Ropivacaine. We noted that duration of motor blockade and post-operative analgesia were significantly prolonged in Group D compared to Group F. Honoura et al ${ }^{[17]}$ in their study observed that addition of demedetomidine to bupivacaine and fentanyl has improved intra operative condition and quality of post-operativeanalgesia without significant maternal or neonatal side effects.

Patients were calm and compose in both the groups. Majority of the patients in dexmedetomidine group had sedation scores of 2 and 3 whereas majority in fentanyl group had sedation score of 1 . This was also statistically highly significant. The sedation properties of dexmedetomidine are far superior to fentanyl. No patients in either group required any other sedative drug during the perioperative period.

We also observed that patients in both the groups were hemodynamicallystable. Even though the decrease in heart rate is known clinical effect of opioid, dexmedetomidine group also showed reduction in heart rate between 30 and 45 minutes of epidural administration, after that the heart rate remained stable in both the groups. None of the patients needed atropine. The mean arterial pressure also showed decrease from the baseline value between 30 and 45minutes after epidural administration in both the groups but were in an acceptable range and never below $70 \mathrm{~mm} \mathrm{Hg}$. Post operatively both the groups were hemodynamically stable. The decrease in heart rate caused by dexmedetomidine can be explained on the basis of their central action were by it decrease sympathetic outflow and norepinephrine release ${ }^{[10,11,12]}$. The stable hemodynamics maybe due to the use of lower volume of local anaesthetic and lower dose of adjuvants.

Incidence of side effects like nausea, vomiting, shivering and urinary retention were similar in both the groups. Two patients in the fentanyl group developed pruritus in the postoperative period which was mild and did not require any treatment and three patients in the dexmedetomidine group suffered from dry mouth. Dryness of mouth is a known complication of $\alpha 2$ agonists. Bajwa $\mathrm{S}$ et al ${ }^{[18]}$ in their study also observed dryness of mouth in $14 \%$ of patients. 
They used $1 \mathrm{mcg} / \mathrm{kg}$ of dexmedetomidine whereas in our study we used a lower dose $25 \mathrm{mcg}$, approximately $0.5 \mathrm{mcg} / \mathrm{kg}$ only. None of the patients in thepresent study developed respiratory depression. This can be explained on the basis of low dose of fentanyl which we used and absence of respiratory depression with dexmedetomidine, which was similar to the previous human studies where researchers found complete absence of clinically detectable respiratory depression ${ }^{[13,19]}$.

Faster onset of action of the local anaesthetic, prolonged duration of analgesia and stable hemodynamic parameters make these agents very effective adjuvants in regional anesthesia.

\section{CONCLUSION}

Epidural dexmedetomidine was better than fentanyl as adjuvant to levobupivacaine for providing early onset of sensory and motor block, prolonged motor block and postoperativeanalgesia and better sedation. Both the drugs reduced the epidural dose of levobupivacaine, with stable and comparable hemodynamics with minimal side effects.

\section{REFERENCES}

1. Luis et al. Epidural anesthesia and analgesia. Their role in post-operative outcome. Anaesthesiology1995; 82:14741506

2. Basse $\mathrm{L}$ et al. a clinical pathway to accelerate recovery after colonic recession. Ann. Surg2000;2322:51-7

3. Myles P.S. power I, Jamozik K. epidural block and outcome after major surjery. MJA - 2002; 536-537.

4. Rigg JR, Jamrozik, Myles PS, Peyton PJ,Parsons RW et al.; MASTER Anesthesia Trial Study Group. Epidural anesthesia and analgesia and outcome of major surgery, A randomized trial. Lancet 2002; 359:1276-82.

5. Foster RH, Markham A. Levobubivacaine .A review of it pharmacology and use as a local anaesthetic Drugs.2000:59:551-79.
6. Gabriel JS, Cordin V. Alpha 2 agonists in regional anesthesia and analgesia. Curr opin Anaesthesiol 2001; 14:751-3.

7. Hohener D, Blumenthal S, Borgat A. Sedation and regional Anesthesiain the adult patients Br.J.Anesthesia. 2008;100:86

8. Solomaki TE, Laitenen JO, Nunntinen LS. A randomized double blind study comparison of epidermal versus intravenous fentanyl infusion for analgesia after thoracotomy. Anesthesiology 1991;75:790-5

9. Lorenzini C, Moriera LB, Ferriera NB. Efficacy of Ropivocaine compared with ropivacaine plus sufentanyl for postoperative analgesia after major knee surgery. Anesthesia 2002; 57:424-8.

10. Bhana N, Goa KL, Mc Clellan KJ. Dexmedetomidinee Drugs. 2000; 59; 26370.

11. Jaakola ML, Salonen M. LehTinen R , Scheinin $H$. The analgesic action of dexmedetomidine ; A novel alpha 2 adrenoreceptor agaonist in healthy volunteers Pain ; 46:281-5.

12. Talk P Richardson CA ScheininM, fisher DM. post-operative pharmacokinetics and sympatholytic effects of dexmedetomidine . Anesth Analg 1997; 85:1136-42.

13. Venn RM, Hell J, Grounds RM. Respiratory effects of dexmedetomidine in the surgical patients requiring intensive care 200;4:302-8.

14. Ozgurel O. Comparison of fentanyl added to Ropivacaine in spinal anesthesia Reg Anesth Pain Med 2003; 28:23.

15. Cherng CH, Ynag CP,Wong CS. Epidural fentanyl speedsthe onset of sensory and motor blocks during epidural Ropivacaine anesthesia.Anaeth Anal 2005;101:134-7.

16. Bajwa SJ,Bajwa SK, Kaur J, Singh G, Arora V, Gupta S, et al. Dexmedetomidine and clonidine in epidural analgesia. Ac comparirive evaluation. Indian $\mathrm{J}$ Anesth. 2011:55:116-21. 
17. Hanoura SE, Hssanin R, Singh R. Intraoperative condition and quality of pot operative analgesia after adding dexmedetomidine to epidural bupivacaine and fentanyl in elective cesarean section using combined spinal-epidural anesthesia. Anesthesia 2013; 7:168-72.

18. Bajwa S, Arora V, Kaur J, Pamar SS. Comparitive evaluation of Dexmedetomidine and Fentanyl for epidural analgesiafor lower limb orthopedic surgeries. Saudi J Anesth 2011;5:365-70

19. Venn RM, Bradshaw CJ, Spencer R, Brealey D Caudwell E, Nughton C, et al. Preliminary UK experience of dexmedetomidine, a novel agent for postoperative sedation in the intensive care unit. Anesthesia; 1999; 54:1136-42. 